\title{
Maria Rosaria Valentini e Laura Mengani, Oggi però nevica, Lugano, Giraffe Bianche, 2020.
}

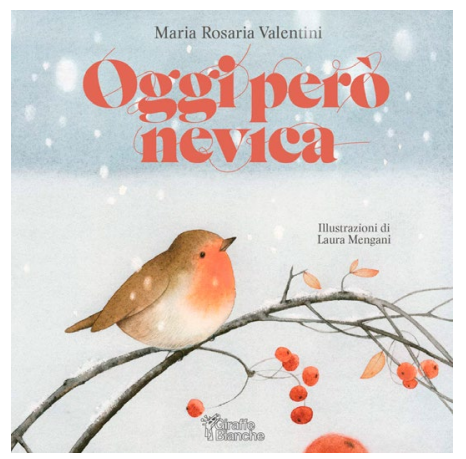

La storia si apre con l'immagine di un papà che non ha né tempo da perdere né pazienza. Oggi però nevica, così, nella casetta sul pizzo della collina, lui e sua figlia restano in casa: ammonticchiano i piatti della colazione sull'acquaio, si affacciano alla finestra con il pigiama e le babbucce e osservano il mondo, al calduccio. Il papà «stacca la spina», pur non essendo né un tostapane, né un ferro da stiro. I fiocchi sono prima magri, nastri di neve lenti, poi si fanno rapidi, infine corrono e la neve scende spessa. Scompaiono la siepe, i ciottoli, l'orto con le verze, i rami di un frassino spuntano per caso, la natura è affogata nel bianco.

Bambina e babbo notano delle impronte di passero, di lepre, di volpe: di quest'ultima si vede la coda «rossa che scivola verso il fosso».

«Il buio arriva al trotto», la mano della bimba trova un nido dentro quella di papà. Entrambi sperano che l'indomani nevichi ancora.

L'albo illustrato Oggi però nevica di Maria Rosaria Valentini (2020), illustrato da Laura Mengani e pubblicato da Giraffe Bianche, nuova e coraggiosa avventura editoriale creata dalla stessa autrice, è un delicato contrappunto tra parole, spazi bianchi, disposizione del testo sulla pagina (le parole hanno una forma, curvano pure), disegno. Si capisce bene che i grafici Federica Tobler e Robin 
Eberwein (rispettivamente classe '96 e '95, diplomati entrambi alla SUPSI nel 2018 e fondatori dello Studio 11×1) ci sanno fare.

Se è vero, come dice Chiara Carminati (2011) nel suo Perlaparola, che «le parole sono perle / chiuse in cuori di conchiglie / quando parli schiudi e sciogli / le collane meraviglie», qui ne abbiamo una dimostrazione, in una situazione narrativa semplice che è anche un canto, una melodia, un testo proprio da leggere ad alta voce: le parole scelte hanno un gusto, si possono masticare, sentire: la «coda rossa verso il fosso», la scomparsa delle verze, della catasta, delle spine del calicanto, dei pioppi affogati nel bianco sono poesia, così come i richiami tra «pizzo - collina - fiocca - ammonticchiare - acquaio - restiamo come stiamo - babbucce - stacca» o «impronte» con «lepre», o il buio che «arriva al trotto».

Le parole producono anche immagini molto potenti: il papà, che all'inizio della storia ha «pazienza zero», «stacca la spina», così la bambina trova con la sua mano un nido dentro la sua. Si potrebbe rappresentare questa storia anche graficamente, con un orologio che segna il tempo delle immagini, ma invece delle lancette, ci sono parole, invece dei secondi e dei minuti, ci sono emozioni.

Insomma, ancora una volta l'autrice di Lugano, publicata da Sellerio e in libreria qualche mese fa con il suo nuovo romanzo Eppure osarono (Francesco Brioschi editore) ha di nuovo prodotto un lavoro di grande qualità, anche in veste di editrice.

Daniele Dell'Agnola 